\title{
STUDIES ON THE RADIOLOGICAL CONTAMINATION OF FISHES I. A CONSIDERATION ON THE DISTRIBUTION AND MIGRATION OF CONTAMINATED FISHES ON THE BASIS OF THE COMPILED DATA OF RADIOLOGICAL SURVEY
}

\author{
TOSHIHARU KAWABATA \\ Department of Food Control, National Institute of Health, Tokyo, Japan
}

(Received: August 25th, 1955)

INTRODUCTION

The nuclear test at Bikini Atoll on March 1, 1954, made an accidental fall of the radioactive dust, so-called "Bikini Ashes", on a Japanese fishing boat, "Fukuryu Maru" No. 5 (99.9 tons). Her crew of 23 afflicted from radiation sickness, which was diagnosed after the boat returned to her home port, Yaizu, on March 14, 1954.

Aside from the radiation hazards of fishermen, another unexpected problem developed when tunas caught by "Fukuryu Maru" were put on the central market of Tokyo Metropolis on March 17, 1954 after they were landed at Yaizu Harbour. Detecting strong radioactivity in these fishes, health authorities of the Government decided to make radiological survey for all fishes caught in the South Pacific. On March 18, the Ministry of Health and Welfare and the Ministry of Agriculture and Forestry requested the Japanese fishing boats which were on the water near Bikini Atoll at the time of the explosion to give an account of the scheduled date of returning to port. Simultaneously, the Government designated five ports to which they should return. The radiological survey by the government sanitary officials at the designated ports was commenced early in the morning on March 19 in cooperation with the health authorities of Metropolis and each Prefecture. The radiological survey by the government inspectors at the five designated ports was, at the later date, transferred to the Metropolis and each Prefecture. But later on, such other prefectures as Osaka, Hyogo, Wakayama, Kochi, Tokushima, Nagasaki and Kagoshima voluntarily initiated similar inspection on the fishes landed at the ports in their respective jurisdiction, because radioactivity was frequently detected from the tunas and other fishes caught in the sea nearer to Japan since the middle of May. The survey was continued till the discontinuation was ordered by the Government at the end of the year 1954.

The author intends to summarize the data on the radiological survey at various ports in Japan as collected by the authorities of Ministry of Health and Welfare in order to obtain information as to the distribution and migration of contaminated fishes and as to the effect of the experimental hydrogen bomb detonation upon the fisheries of Japan. 


\section{Transition in the Catch of Radiologically Contaminated Fishes}

1. In the early period of inspection (March-early April, 1954) radioactivity found in fishes was generally considered due to the external adhesion of radioactive material. In fact higher counts were detected to certain extent in one fish, all the fishes in a ship or hold were used to be condemned at a time, consequently such a disposition caused occasional problems (Fig. 1). On the contrary, from the middle of April, much higher counts were detected chiefly in the gill or intestinal organs of fishes, whereas a tendency was noted toward decrease in the surface count, which was noticed among tunas and other fishes caught in the sea both coastal and pelagic (Fig. 2). The fact may suggest that the contamination of fish is due chiefly to their food but not to the external adhesion.

While, since that time, contaminated tunas were rather sporadically found and at most scores of fishes were found in one hold. On the other hand, the count detected in a fish became higher day by day until it reached 500-1,500 cpm when measured according to the regulation promulgated by the Ministry of Health and Welfare (at the distance of $10 \mathrm{~cm}$ from the surface of fish). For example, such high pollution was demonstrated in dolphin (Coryphaena hippurus Linné) caught near the coast of Formosa (Fig. 3).

2. From June to July, 1954, pelagic fisheries demonstrated a down trend in contrast to the up trend of coast fisheries. Consequently, the amount of discarded fishes at five designated ports decreased and those at various other ports fervently increased (Fig. 4 and 5).

It was found that the shoal of contaminated fishes around Formosa came up along to the Kuroshiwo Stream until it reached near Kyushu. However, the subsequent course of the shoal is not clearly illustrated in Fig. 5, probably because of few fishing boats was operating on the sea north or Kyushu during that season.

3. Since the middle of July, 1954, highly contaminated fishes were again discovered in the fishing boats returned from the area around Truk and Guam Isls., moreover, more fishes discarded were yielded per a ship. The facts are indicative of the increase of polluted fishes in number among the all hauled fishes. For example, 5,020 cpm in "Hime Maru" on August 17 at Tokyo Harbour and 7,360 cpm in No. 12 "Kuroshio Maru" on August 18 at Misaki Port were detected. Condemned fishes of a ship mounted up to $4,000-16,000 \mathrm{Kg}$, so that discarding by burying became impracticable, consequently, throwing those fishes in the sea were compelled (Fig. 6). A contaminated fish was caught at the sea off Jogashima near Misaki, Kanagawa Prefecture on August 23, off Otsu, Ibaraki Prefecture and Sashima near Yokosuka, Kanagawa Prefecture on August 31 respectively. Those inshore fishes were sail fish (Isatiophorous orientaris), yellow fin tuna (Neothunnus macropterus) or big eye tuna (Parathunnus mebachi) respectively.

On September 5, strong radioactivity was detected from the fishes (sail fish) weighing about $2,400 \mathrm{Kg}$ in total caught by three fishing boats in the sea 


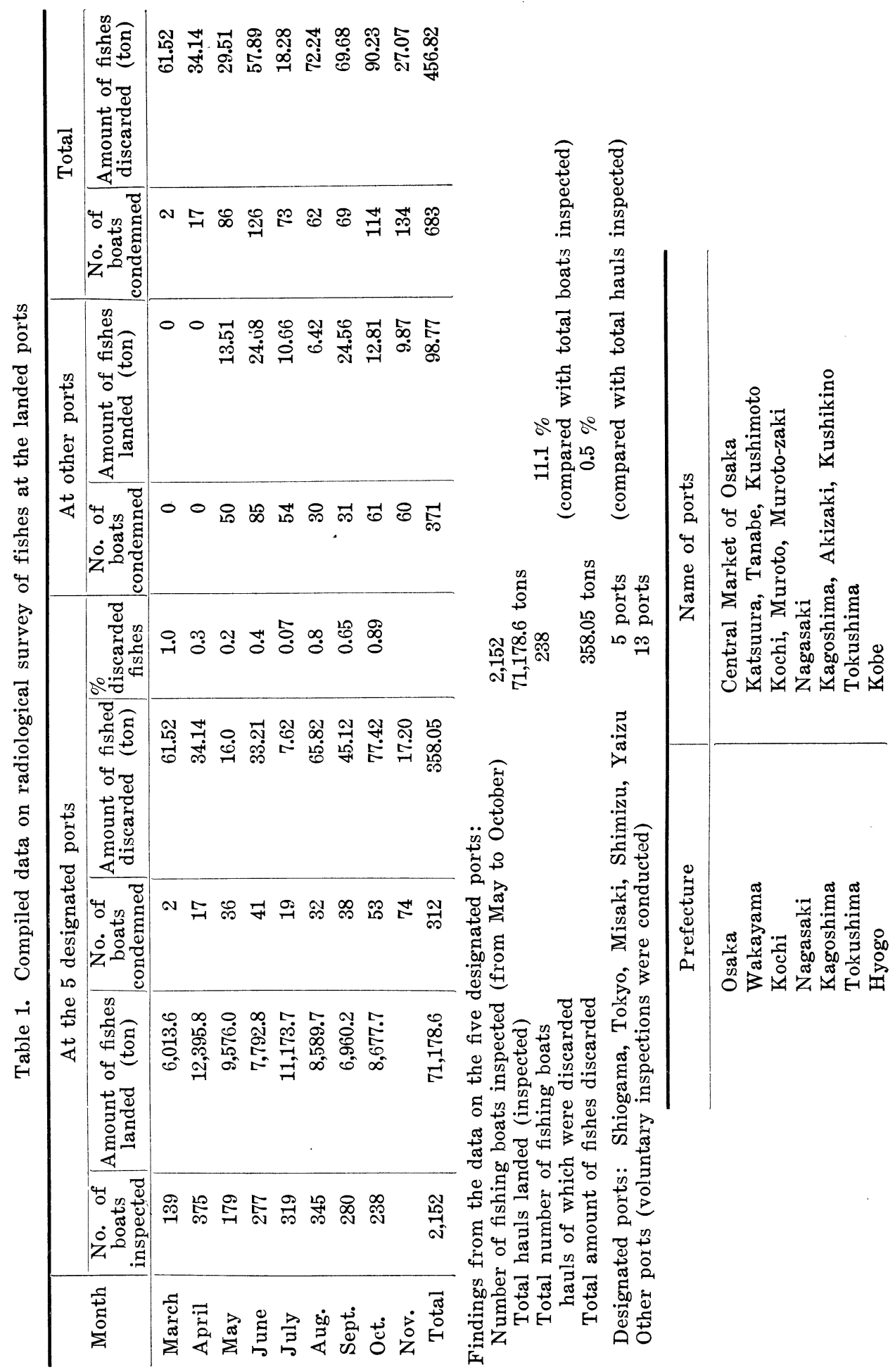


off Miho near Shimizu Port, Shizuoka Prefecture. All of them had to be discarded. It is noteworthy that all these polluted fishes were caught in the sea only 10-15 miles off the shore.

The above may be suggesting that the accumulation of certain long-lived radioactive elements in fish bodies is causing the high activity detected in them even several months after the nuclear tests at Bikini Atoll during May to March, 1954, and the same may be causing its continuance for a long period of time even until the end of the year, when the radiological inspection was discontinued by the order of the Ministry of Health and Welfare. And what is more, many fishes caught in the adjacent sea were found to be highly contaminated and the number in fishing boats whose hauls were discarded became much larger.

Table 2. Change of the radioactivity detected in the hauls

(1) At the five designated ports:

\begin{tabular}{rrrrrrrrrrr}
\hline cpm & Mar. & Apr. & May & June & July & Aug. & Sept. & Oct. & Nov. $\begin{array}{c}\text { Avevage } \\
(\%)\end{array}$ \\
\hline$>5,000$ & - & - & - & - & 3.0 & 3.5 & 1.1 & 1.3 & - & 0.8 \\
$>3,000$ & - & - & 9.7 & - & 9.1 & 5.8 & 2.2 & 0.6 & 1.1 & 1.8 \\
$>1,000$ & - & 1.8 & 5.8 & 21.8 & 15.1 & 22.4 & 32.6 & 14.4 & 11.8 & 14.3 \\
$>500$ & - & 1.8 & 10.3 & 21.8 & 21.2 & 29.4 & 30.3 & 22.9 & 22.6 & 18.8 \\
$>100$ & 100 & 96.4 & 83.2 & 56.5 & 51.5 & 38.8 & 33.7 & 60.8 & 64.5 & 64.3 \\
Total $(\%) 100$ & 100 & 100 & 100 & 100 & 100 & 100 & 100 & 100 & 100
\end{tabular}

(2) At the other 13 ports:

\begin{tabular}{|c|c|c|c|c|c|c|c|c|c|c|}
\hline cpm & Mar. & Apr. & May & June & July & Aug. & Sept. & Oct. & Nov. & $\begin{array}{c}\text { Average } \\
(\%)\end{array}$ \\
\hline$>3,0$ & & & - & 0.8 & 0 . & 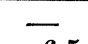 & 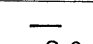 & - & - & 0. \\
\hline$>1,000$ & & & 6. & 11 & & 0 & & & 5. & \\
\hline$>500$ & & & 19 & 11 & 20 & 12 & 17 & 16 & 10.5 & 15.7 \\
\hline$>100$ & & & 73. & 85.6 & 74.6 & 80.6 & 73. & 72.9 & 84.3 & 78.5 \\
\hline Total (\% & & & 100 & 100 & 100 & 100 & 100 & 100 & 100 & 100 \\
\hline
\end{tabular}

Note: Figures in each column indicate the relative frequency $(\%)$ among the contaminated fishes, in proportion to the radioactivity detected.

Radioactivity of fish was measured at distance of $10 \mathrm{~cm}$ from the surface of fish to an end window GM tube, and fishes were discarded when their activity was found more than $100 \mathrm{cpm}$.

\section{Discussion}

(Areas where probably yield contaminated fishes)

Many of the highly contaminated fishes were caught here and there even after several months since the test explosions. The contamination of fishes was presumed to continue for a considerably long period of time thereafter, although neither the radioactive elements contained excepting $\mathrm{Zn}^{65}$, which will be reported in the author's subsequent paper, nor the biological half-life in fishes had been clearly found. Therefore, attention should be paid upon the areas where probably yield contaminated fishes. The author intends to present some supposition on this problem on the basis of the compiled data on the radiological survey.

1. The movement of the contaminated sea water mass

Radiological contamination of living subjects, directly or indirectly it may be, and the movement of the contaminated water mass were supposed to take 
place continuously, until the outflow of radioactive substances ceased from the source, Bikini Atoll or other places, where test explosions were conducted. In this sense, North Equatorial Current would be of significance. However, it is presumed that the radioactive substances contained in the current must be diluted before it comes near Japan Islands, because it takes about 4-5 months for the current to come to the coast of Japan, during which time, intermixture, diffusion and decay of radioactive elements must take place. This presumption has been verified recently by Miyake et $\mathbf{a l}^{\left.1{ }^{1},{ }^{2}\right)}$ of the Meteorological Research Institute. However, attention should be paid on the existence of such living subjects as planktons in the sea water which condense the radioisotope in their bodies and as the small-sized fishes which subsist on them.

Radioactivity of several cpm/l of sea water from Suruga Bay ${ }^{3)}$ and scores $\mathrm{cpm} / \mathrm{g}$ of plankton in it was proved in late September, therefore, the investigation on the transference of sea water as well as contamination in planktons would become necessary considering the possibility of contamination of adjacent sea water especially of inshore fishes.

\section{The migration of tunas and other fishes}

Haul of contaminated fishes at the area to where they migrate is secondarily important problem. In this sense, North Equatorial Current and some other adjacent currents come to the front. Tunas are generally believed to migrate along with current. In the sea south of Subtropical Converzence Zone, which moves to north and south in summer and winter respectively, expansion and reduction of living circle alternately take place every year, thus there would be a possibility of appearance of fishes at the sea around $\mathrm{N} 30^{\circ}$ in summer. On the other hand, eastern and western areas are included in the same living circle, therefore, migration of contaminated fishes to considerably wide extent can be anticipated. The appearance of many contaminated fishes at the coast of Formosa and of south Kyushu since the middle of April to July was considered to have been resulted from their migration.

In April or May, many contaminated fishes were caught near Formosa to where the contaminated current stream moving at a speed of 1-2 knots/hr. should not have reached. Subsequent detection of radioactivity in the gastric contents of dolphin (Coryphaena hippurus) and other fishes indicated the transference of contaminated current as well as contamination of small-sized fishes and planktons they subsist on.

Catch of contaminated fishes near Guam and Bonin Isls. can be interpreted without discrepancy that they were in the Ogasawara Current which is a tributary of the North Equatorial Current. The catch of contaminated tunas near Truk Island elicided much problem, but it may be attributed to the mingle of the contaminated sea water, because the island in question is situated near the northern edge of the North Equatorial Counter Current. The width of a current is usually variable from time to time and there may be some volutex at 
the border of currents, therefore, an intermingle of sea water must take place. When we made observation near Ponape Islands, which is located in the up-stream of the Truk Island, no activity in the sea water was detected. Subsequently, the data of survey with sea water taken near Oroluk Is. conducted by Miyake et al ${ }^{1)}$ demonstrated a considerable high count as $200 \mathrm{cpm} / \mathrm{l}$, which is of some help to give explanation to the catch of contaminated fishes in the areas near Truk Isls.

Attention should be directed to the transference of contamination into the fishing ground where once had been judged to be safe at the time of our expedition, as well as to the possibility for the fishes there to become radioactivity bearer.

Fig. 7. Summarized distribution of fishing boats the hauls of which were discarded from March to August

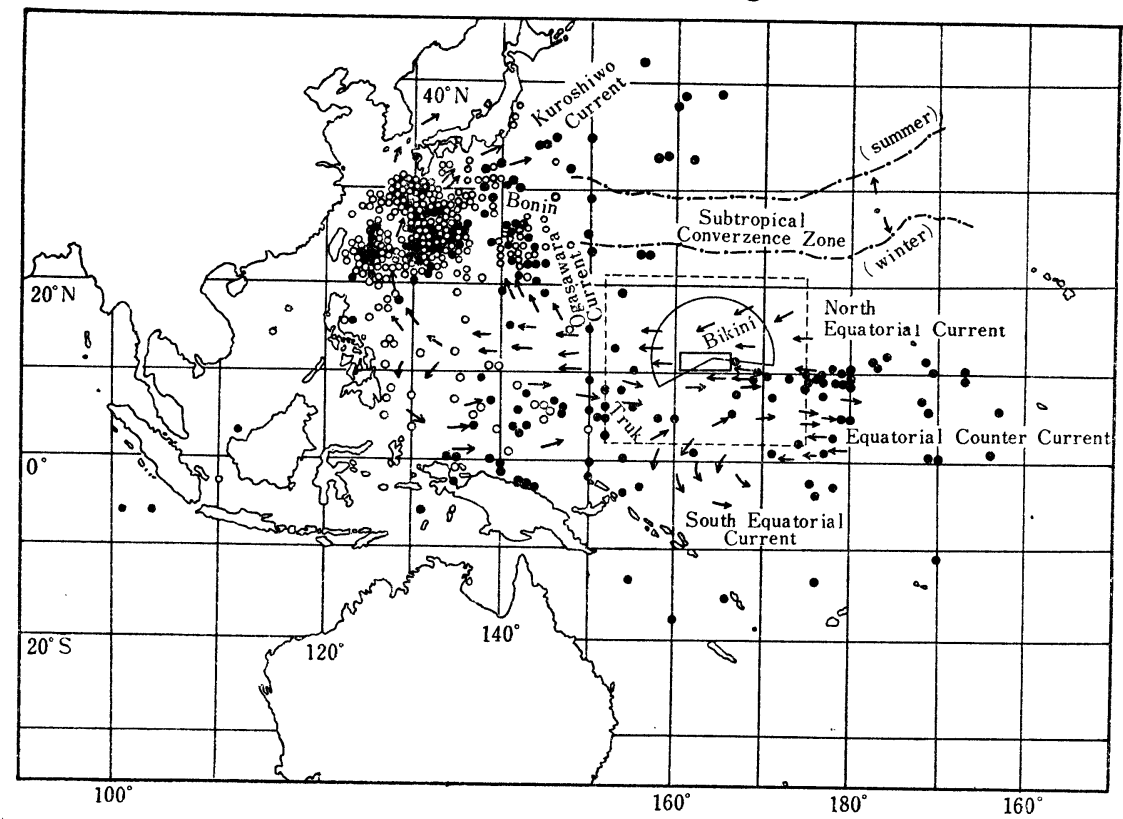

indicates the boat returned to the designated port indicates the boat returned to the other port

3. Other possibility for the catch of contaminated fishes at the unexpected areas As shown in Fig. 7, many highly contaminated tunas were caught in the fishing ground near Solomon Isls., south to the South Equatorial Current during September to October. The fact may offer great discrepancy in the conception that tunas are believed to migrate along with current. According to Nakamura of the Nankai Regional Fisheries Research Laboratory, such species as yellow fin tuna (Neothunnus macropterus) may be considered to break through between the North Equatorial and Counter Currents and move seasonably in mass. The 
catch of contaminated tunas in the fishing ground of far southern to the Equator might be attributed to the seasonal movement of some species of fish. The fact may suggest the existence of the ability in some species of tunas to break through currents, however, further investigation would become necessary in considering the possibility of the appearance of tunas contaminated at the sea near Bikini in an unexpected area to where they break through currents.

An opinion ${ }^{5)}$ has been presented that black marline (Makaira mazara) or sail fish (Istiophorous orientaris), to which the current is of little significance as living circle, may break through current without difficulty. Anticipation has been expressed by the author to the possibility of the appearance of such species of fishes in an unexpected area.

\section{SUMMARY}

1. The contamination of fishes was presumed to continue for a considerably long period of time thereafter.

2. The movement of the contaminated sea water mass was supposed to have close relation to the distribution of contaminated fishes. In this sense, North Equatorial Current, up-stream of Kuroshiwo Current, and its tributary would be a significance.

3. Tunas are generally believed to migrate with current. Therefore, the course of migration may offer secondarily important problem upon the catch of contaminated fishes. In this sense, North Equatorial Current and some other adjacent currents come to the front.

4. The fact that the catch of contaminated tunas in the fishing ground near Solomon Isls. or other unexpected area might be attributed to the result of movement of tunas broken through currents, indicating other possibility of some species of tunas migrating along with current. Anticipation have been expressed by the author to the possibility of the appearance of such species of fishes in an unexpected area.

\section{ACKNOWLEDGEMENT}

The present paper is based on the data of the radiological inspection conducted by the health authorities of Metropolice and each Prefecture. The author wishes to express his thanks for the authorities of the Milk and Meat Sanitation Section of the Ministry of Health and Welfare in giving the precious data on the radiological survey.

\section{REFERENCES}

1) Y. Miyake, Y. Sugiura and K. Kameda: Radioactivity detected in sea water near Japan. "Nippon UNESCO Kokusai Iinkai, Kaiyo Shigen Kaihatsu Hokoku" in 1954, 81-82 (In Japanese)

2) Y. Sugiura: Artificial radioactivity found in sea water. "Sokko Jiho", 22, 66 73 (1955) (In Japanese)

3) Record on the 15th Meeting of the Atomic Injury Investigation and Research Committee of Japan, Sept., 28, 1954

4) H. Nakamura: Personal communication

5) H. Yabe: Summarized Reports on "Shunkotsu Maru", IV. On fisheries, "Shizen", 9, 3337 (1954) (In Japanese) 
Fig. 1. Distribution of fishing boats the hauls of which were discarded (March 17 to 31 )

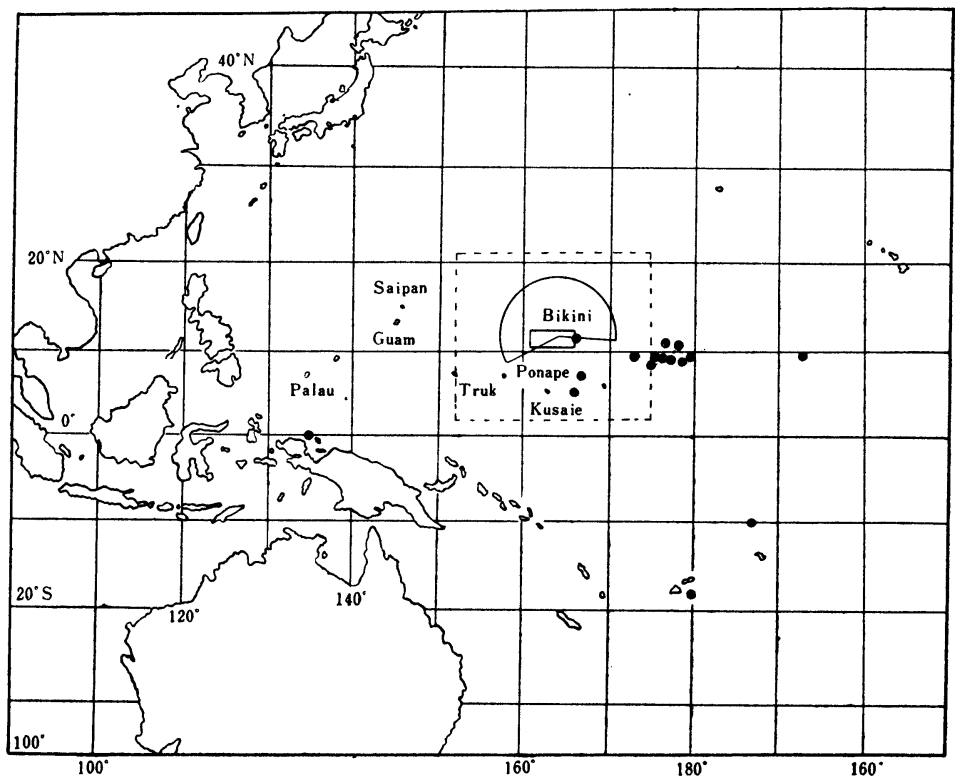

- indicates the boat returned to the designated port

$O$ indicates the boat returned to the other port

Fig. 2. Distribution of fishing boats the hauls of which were discarded (April 1 to 30 )

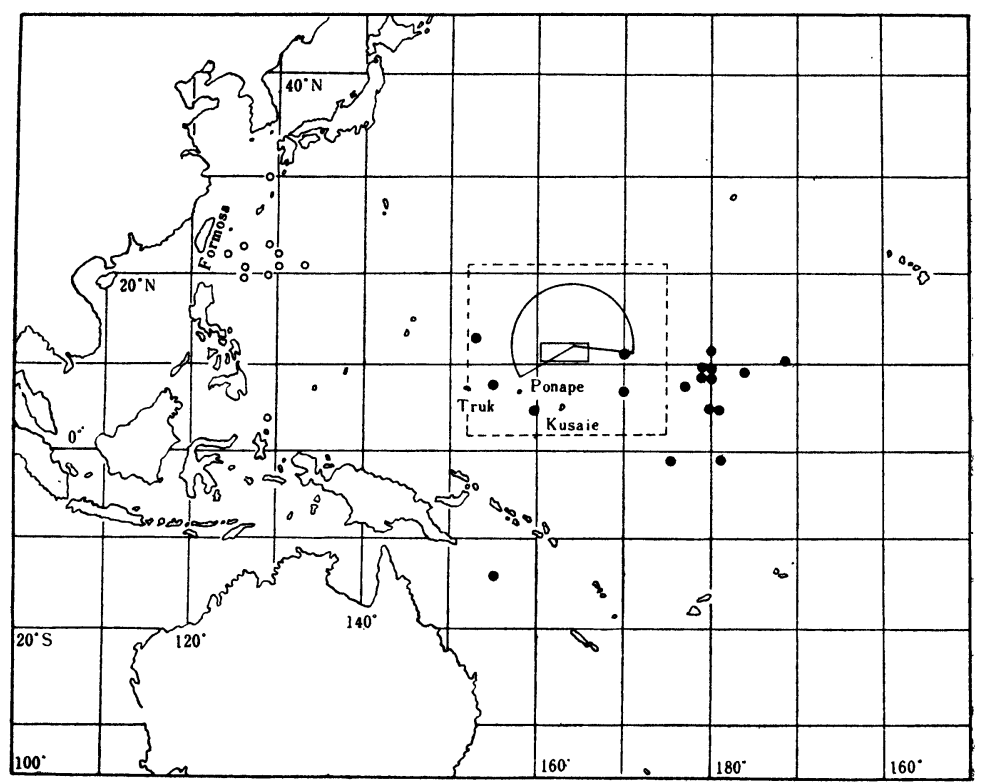

- indicates the boat returned to the designated port

$O$ indicates the boat returned to the other port 
Fig. 3. Distribution of fishing boats the hauls of which were discarded (May 1 to 31 )

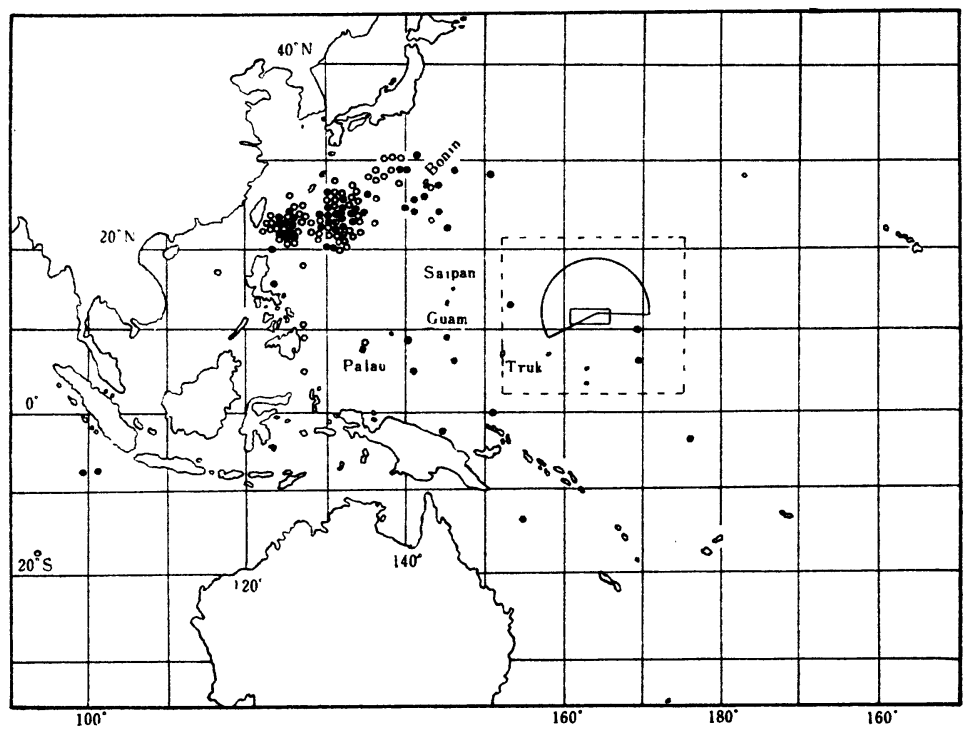

indicates the boat returned to the designated port

$O$ indicates the boat returned to the other port

Fig. 4. Distribution of fishing boats the hauls of which were discarded (June 1 to 30 )

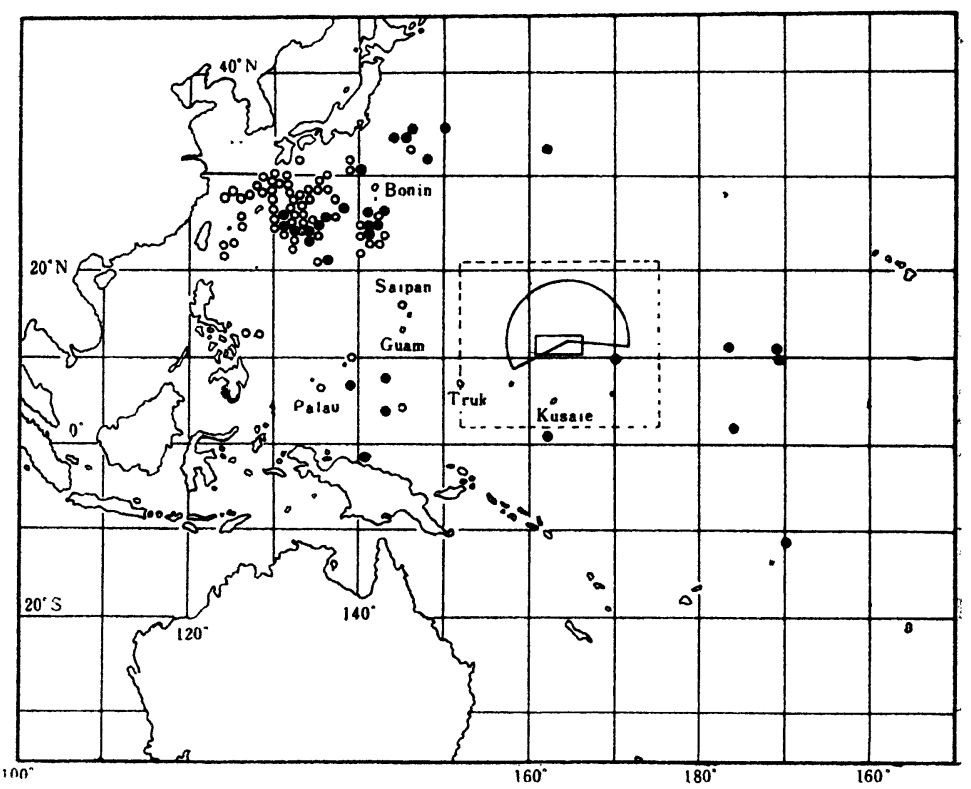

indicates the boat returned to the designated port

$O$ indicates the boat returned to the other port 
Fig. 5. Distribution of fishing boats the hauls of which were discarded (July 1 to 31 )

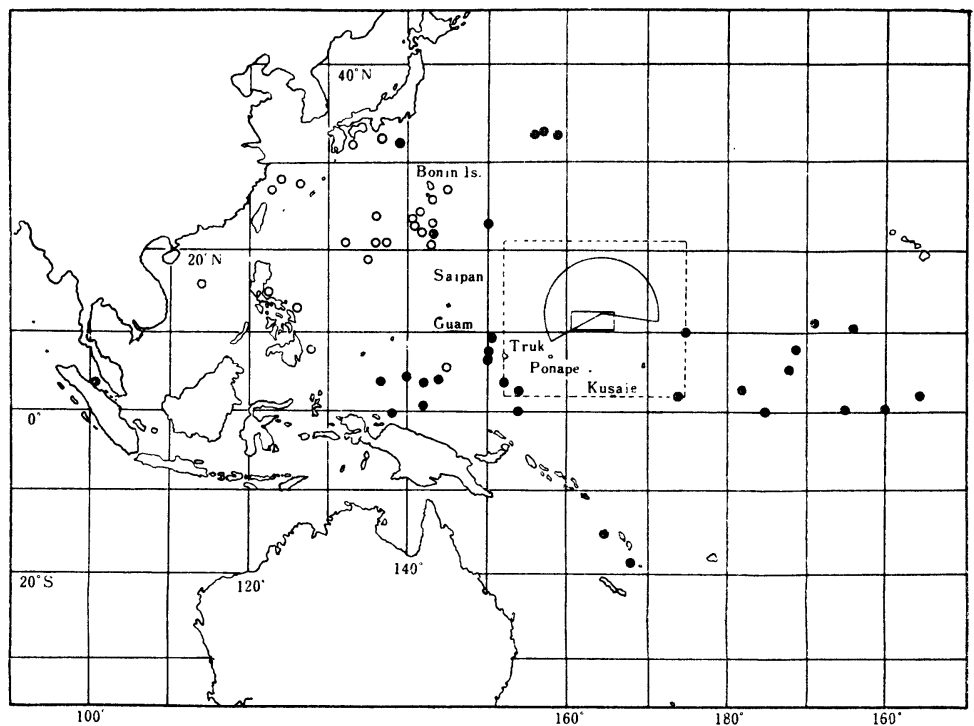

indicates the boat returned to the designated port

indicates the boat returned to the other port

Fig. 6. Distribution of fishing boats the hauls of which were discarded (August 1 to 31 )

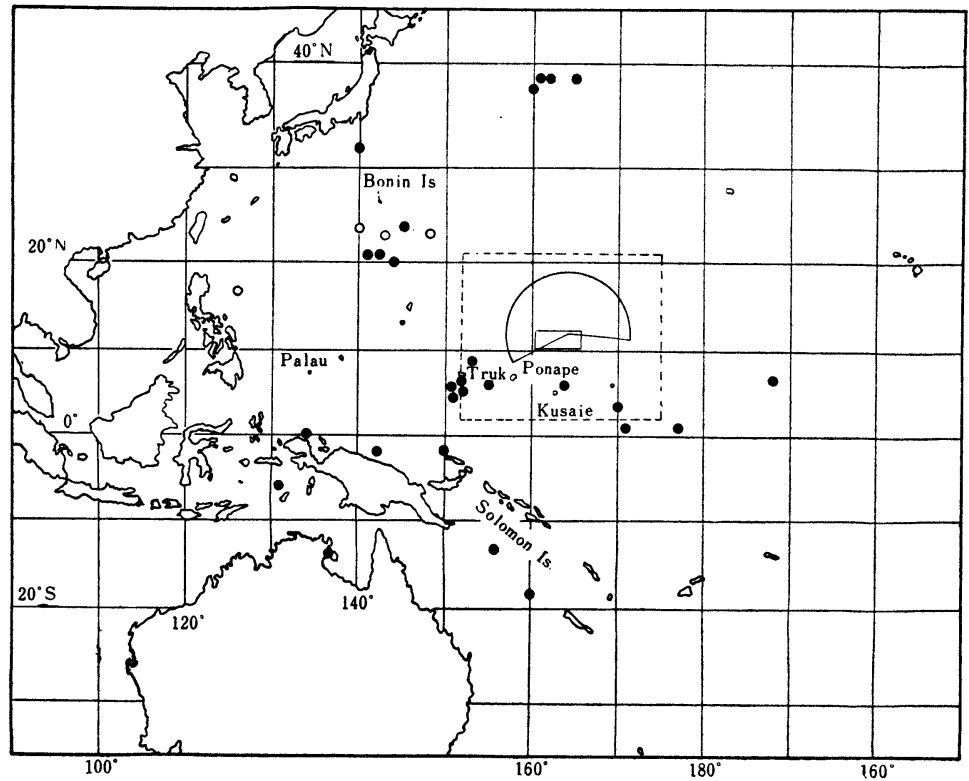

- indicates the boat returned to the designated port

$\bigcirc$ indicates the boat returned to the other port 